\title{
Symptomatic COVID-19 infections in outpatient image-guided corticosteroid injection patients during the lockdown phase
}

\author{
Connie Y. Chang ${ }^{1,4}$ (D) Anand Prabhakar ${ }^{2,4}$. Steven J. Staffa ${ }^{3,4} \cdot$ Jad S. Husseini $^{1,4} \cdot$ Arvin B. Kheterpal $^{1,4}$. \\ F. Joseph Simeone ${ }^{1,4} \cdot$ Miriam A. Bredella ${ }^{1,4}$
}

Received: 19 July 2020 / Revised: 28 September 2020 / Accepted: 16 October 2020 / Published online: 27 October 2020

(C) ISS 2020

\begin{abstract}
Background Musculoskeletal pain is a debilitating problem treated with image-guided corticosteroid injections. During the COVID-19 pandemic, multiple societies issued caution statements because of the unknown effect of corticosteroids on the patient's immune system. The purpose is to determine if image-guided corticosteroid injections administered during the COVID-19 lockdown phase were associated with a higher infection rate compared to the general population.

Materials and methods In a prospective study, patients undergoing image-guided corticosteroid injections for pain management during the lockdown phase between April 15 and May 22, 2020, were enrolled. One month after the injection, patients were surveyed by telephone for any COVID-19-related symptoms, and the electronic medical record (EMR) was reviewed for symptoms and test results.

Results Seventy-one subjects were recruited, 31 (44\%) females, 40 (56\%) males, ages $58 \pm 17$ (20-92) years. Follow-up was available in $66(93 \%)$ of subjects, $60(91 \%)$ by phone survey and EMR, $6(9 \%)$ by EMR only, $45 \pm 22$ (19-83) days after injection. One $(1 / 66,1.52 \%$; $95 \%$ CI $0.04-8.2 \%)$ 25-year-old male subject developed symptomatic infection 19 days after a tibiotalar injection. The prevalence of COVID-19 cases in the state of Massachusetts was $0.91 \%(62,726 / 6,892,503)$ during the study period. There was no significant difference in the rate of occurrence of new cases of COVID-19 infection between the corticosteroid injection group and the general population $(p=0.44)$.

Conclusion Image-guided corticosteroid injections for pain management performed during the lockdown phase of the COVID19 pandemic were not associated with a higher infection rate compared to the general population.
\end{abstract}

Keywords COVID · Infection · Corticosteroid · Injection · Image guidance

\section{Introduction}

Back and joint pain are common debilitating problems, which can be treated with corticosteroid injections [1-3]. With the sudden arrival of the COVID-19 pandemic and the state

Connie Y. Chang

cychang@mgh.harvard.edu

1 Division of Musculoskeletal Imaging and Intervention, Department of Radiology, Massachusetts General Hospital, 55 Fruit Street, Yawkey 6E, Boston, MA 02114, USA

2 Department of Radiology, Newton-Wellesley Hospital, Newton, MA, USA

3 Department of Anesthesiology, Critical Care and Pain Medicine, Boston Children's Hospital, Boston, MA, USA

4 Harvard Medical School, Boston, MA, USA mandate to halt elective procedures, many planned corticosteroid injections were cancelled or rescheduled for an unknown future date. On March 19, 2020, the British Society of Skeletal Radiologists published recommendations stating that "intraarticular corticosteroid, soft tissue, and perineural injections should be avoided, whenever possible during the COVID-19 pandemic to reduce the risk of reduced immunity to viral exposure" [4]. On March 25, 2020, the British Society for Rheumatology recommended extreme caution and serious discussion with the patient prior to proceeding corticosteroid injections, as well as use of minimum doses to achieve pain relief [5]. On April 7, 2020, consensus recommendations from the Association of Anaesthetists stated "intra-articular corticosteroid injections could increase the risk of viral infection" and recommended use of dexamethasone and betamethasone over other corticosteroids and decreasing the dose [6]. As the disease peak passed in our region, we re-evaluated the risks and benefits of corticosteroid injections in the context of this novel 
viral disease for which there is a latent period during which the patient can carry the virus but not yet be symptomatic [7]. For some patients who have severe debilitating pain, the corticosteroid injection may substantially improve their quality of life. However, systemic absorption of locally injected corticosteroids may affect the response by two potential mechanisms: (1) corticosteroids may directly inhibit the immune system and (2) corticosteroids can depress the hypothalamicpituitary-adrenal (HPA) axis for up to $2-4$ weeks, inhibiting the body's stress response in an acute illness [8]. The latter is more likely to play a role in potential increased infection risk following corticosteroid injections, given the long latent period between exposure and presentation of symptoms [7].

Our practice decided to approach these injections with caution, selecting only patients with severe pain, and following their course to assess whether the injections were associated with a higher COVID-19 infection rate as suggested by the Spine Intervention Society on May 8, 2020 [9]. The purpose of our study was to determine infection rates following imageguided corticosteroid injections for pain management compared to the COVID-19 infection rate in the general population during the lockdown phase. We hypothesized that imageguided corticosteroid injections for pain management are not associated with an increased risk of symptomatic COVID-19 infection.

\section{Materials and methods}

This prospective study conducted at two hospitals was IRB approved and HIPAA compliant. Verbal consent for participation in the study was obtained as per IRB protocol.

\section{Study subjects}

Adult patients who were scheduled for an image-guided injection at our hospital (a large academic center) and at an affiliated community hospital were enrolled in the study. Inclusion criteria were severe pain and a scheduled imageguided corticosteroid injection. Exclusion criteria were inability to adhere to physical distancing following the injection, pregnancy, and allergic reaction to injectate. A physician called each patient prior to the injection to discuss the procedure; the lack of information about the risk of steroid injections during the COVID-19 pandemic was specifically addressed during this conversation.

\section{Image-guided corticosteroid injections}

Injections at the academic center were performed by a fellowship-trained musculoskeletal radiologist with at least 3 years of post-fellowship experience, or by musculoskeletal fellows supervised by the musculoskeletal radiologists.
Injections at the community hospital were performed by a radiology assistant with 8 years of procedure experience and supervised on-site by the same musculoskeletal radiologists. Because of the COVID-19 pandemic, extra measures in scheduling and periprocedural practices were instituted to ensure physical distancing while the patient was at the hospital, including doubling the normal scheduled procedure duration so that no patient would have to wait in the waiting room, calling the patients the day before to go over the consent process to minimize their time in the procedure room on the day of the procedure, having an extra check-in in the lobby to prevent patients from coming up to the radiology area from the lobby more than $10 \mathrm{~min}$ before their appointment time, directly escorting patients from radiology check-in to the procedure room, instructing the patients to wear clothing that would preclude their need to change into hospital gowns (if possible) and if necessary, using disposable paper gowns instead of cloth gowns, using verbal consent for the procedure so that the patient did not have to touch any pens or clipboards, and vigorously cleaning every surface between each patient. All patients were called the day before the exam to (1) screen for symptoms of COVID-19 infection and (2) consent for the procedure, which included a clear statement of the unclear risks of corticosteroids during the COVID-19 pandemic.

All injections were performed under thorough sterile technique. For personal protective equipment, the patients had surgical masks distributed by the hospital. The radiologists and technologists also had surgical masks and eye protection or face shields. The injection site was cleaned prior to injection with betadine or chlorhexidine and the sterile field was established with drapes or towels. Injections were performed under either fluoroscopic or ultrasound guidance. For fluoroscopically guided injections, confirmation of the appropriate injection pattern was performed with iodinated contrast injection (Omnipaque, $300 \mathrm{mgI} / \mathrm{mL}$, GE Healthcare, Piscataway, $\mathrm{NJ}$ ). Corticosteroid (betamethasone sodium phosphate and acetate injectable suspension $(6 \mathrm{mg} / \mathrm{mL}$, American Regent Inc., Shirley, NY; dose 6-21 mg), triamcinolone acetonide injectable suspension $(40 \mathrm{mg} / \mathrm{mL}$, Bristol Myers Squibb Company, New York, NY; dose 40-80 $\mathrm{mg})$, methylprednisolone acetate $(40 \mathrm{mg} / \mathrm{mL}$, Pfizer, New York, NY; dose $60 \mathrm{mg}$ ), or dexamethasone $(4 \mathrm{mg} /$ $\mathrm{mL}$, Fresenius Kabi, Lake Zurich, IL; dose $10 \mathrm{mg}$ ) with or without anesthetic (lidocaine 1\% (AuroMedics Pharma LLC, E. Windsor, $\mathrm{NJ} ; 1-4 \mathrm{~mL}$ ) or ropivacaine $0.2 \%$ (AuroMedics Pharma LLC, E. Windsor, NJ; 1-5 mL)) or bupivacaine $0.5 \%$ (Hospira, Inc, Lake Forest, IL; 2$4 \mathrm{~mL}$ ) was then injected. Following the injection, the patient was instructed to physically distance for $1-2$ weeks, based on the possibility of suppression of the immune system and HPA-axis $[10,11]$. 


\section{Post-procedure survey}

At least 1 month (28 days) after the injection, the patient's electronic medical record (EMR) was reviewed for hospitalizations, emergency room or clinic visits for COVID-19 symptoms, and for COVID-19 test results (virus and antibody). The patients were called and asked the survey questions shown in Fig. 1. Patients were considered lost-to-follow-up if (1) they could not be reached by phone after two attempts and (2) there was no clinical information in the EMR at least 1 month (28 days) after the procedure. One month was chosen to examine potential immunosuppressive effects of systemic corticosteroid exposure on infection rate. A time interval of 28 days would also allow sufficient time for patients to become symptomatic [12].

\section{Statistical analysis}

Categorical data are presented as frequencies and percentages and continuous data are presented using means and standard deviations. Univariate analyses were performed using Fisher's exact test, and 95\% exact binomial confidence intervals were calculated for proportions (Stata version 16.0, StataCorp
LLC., College Station, TX). A two-tailed $p<0.05$ was considered statistically significant.

\section{Results}

Seventy-one study subjects were recruited between April 15, 2020 (the date of the first corticosteroid injection since the beginning of the lockdown) and May 22, 2020 (Governor Baker of Massachusetts announced the transition from lockdown to phase I recovery on May 18, 2020, and businesses and offices began to reopen on Monday May 25, 2020; May 22 was the last business day before the reopening and the last day that injections were performed) (Fig. 2) [13]. The patient demographics and types of corticosteroid injections performed are listed in Table 1. There were 38/71 (54\%) using triamcinolone, 31/71 (44\%) using betamethasone, 1/71 (1\%) using methylprednisolone, and 1/17 (1\%) using dexamethasone.

Follow-up was available in 66 (93\%) of subjects. Sixty (91\%) had follow-up by phone survey and by EMR, and 6 (9\%) by EMR only. Five (7\%) of subjects were lost-to-followup. Follow-up occurred $54 \pm 26$ (range 28-110) days after the

Fig. 1 Post-procedure survey

\begin{tabular}{|c|c|c|}
\hline \multicolumn{3}{|c|}{ injection? } \\
\hline & $\circ$ & Fever or feeling feverish \\
\hline & $\circ$ & Sore throat \\
\hline & $\circ$ & New cough (not related to chronic condition) \\
\hline & $\circ$ & $\begin{array}{l}\text { New nasal congestion or new runny nose (not related to seasonal } \\
\text { allergies) }\end{array}$ \\
\hline & $\circ$ & Muscle aches \\
\hline & $\circ$ & New loss of smell \\
\hline & $\circ$ & New loss of taste \\
\hline & $\circ$ & New shortness of breath \\
\hline$\circ$ & \multicolumn{2}{|c|}{ Dizziness } \\
\hline$\circ$ & \multicolumn{2}{|c|}{ Headache } \\
\hline o & \multicolumn{2}{|c|}{ Nausea/vomiting } \\
\hline$\circ$ & \multicolumn{2}{|c|}{ Diarrhea } \\
\hline$\circ$ & \multicolumn{2}{|c|}{ Abdominal pain } \\
\hline$\circ$ & \multicolumn{2}{|c|}{ Changes in your toes } \\
\hline$\circ$ & \multicolumn{2}{|c|}{ Other? (fill in) } \\
\hline 0 & \multicolumn{2}{|c|}{ No symptoms } \\
\hline
\end{tabular}

Have you had a COVID-19 test? Yes/No

If yes, what kind of test? Virus/Antibodies? What were the results? 
Table 1 Subject demographics and types of corticosteroid injections
Demographic

Study population

$(n=71)$

\begin{tabular}{|c|c|}
\hline \multicolumn{2}{|l|}{ Age } \\
\hline Mean \pm SD & $58 \pm 17$ \\
\hline Range & $20-92$ \\
\hline \multicolumn{2}{|l|}{ Sex } \\
\hline Female & $31(44 \%)$ \\
\hline Male & $40(56 \%)$ \\
\hline \multicolumn{2}{|l|}{ Injection side } \\
\hline Left & $28(39 \%)$ \\
\hline Right & $30(42 \%)$ \\
\hline Midline (epidural steroid injections) & $8(11 \%)$ \\
\hline Bilateral & $5(7 \%)$ \\
\hline \multicolumn{2}{|l|}{ Comorbidities } \\
\hline Body mass index (BMI) & $\begin{array}{l}28.0 \pm 6.0 \\
\quad(19.1-45.9)\end{array}$ \\
\hline Diabetes & $5(7 \%)$ \\
\hline Hypertension & $30(42 \%)$ \\
\hline Hypertension on ACE-I or ARB & $12(17 \%)$ \\
\hline Immunocompromised $*$ & $7(10 \%)$ \\
\hline \multicolumn{2}{|l|}{ Days from injection patient was followed up } \\
\hline Mean \pm SD & $33 \pm 2$ \\
\hline Range & $28-43$ \\
\hline \multicolumn{2}{|l|}{ Imaging modality for guidance } \\
\hline Fluoroscopy & $64(90 \%)$ \\
\hline Ultrasound & $7(10 \%)$ \\
\hline \multicolumn{2}{|l|}{ Type of injection } \\
\hline Joint/bursa/tendon sheath/soft tissue & $51(72 \%)$ \\
\hline Hip & $10(14 \%)$ \\
\hline Shoulder (glenohumeral) & $14(20 \%)$ \\
\hline Facet & $5(7 \%)$ \\
\hline Biceps brachii tendon sheath & $6(8 \%)$ \\
\hline Tibiotalar, subtalar & $4(6 \%)$ \\
\hline Sacroiliac & $3(4 \%)$ \\
\hline $\begin{array}{l}\text { Other (knee, third intermetatarsal space, acromioclavicular joint, proximal tibial-fibular } \\
\text { joint, suprascapular nerve, occipital nerve, greater trochanteric bursa) }\end{array}$ & $9(13 \%)$ \\
\hline Spine (epidural and nerve root) & $20(28 \%)$ \\
\hline
\end{tabular}

$A C E-I$, angiotensin-converting enzyme inhibitors; $A R B$, angiotensin II receptor blockers

*Immunocompromised subjects included 2 with renal insufficiency, 1 with renal transplant, 1 with leukemia on chemotherapy, 1 with multiple sclerosis on ocrelizumab injection. Nine subjects had COVID-19 tests $45 \pm 22$ (19-83) days after their injection. One $(1 / 66,1.52 \%) 25$-year-old male subject, BMI 39, who could not be reached by phone, had a note in the EMR indicating that he developed COVID-19 symptoms 19 days after his right tibiotalar joint injection (triamcinolone $60 \mathrm{mg}$, ropivacaine $1 \mathrm{~mL}$ ), and had a positive test 21 days after his injection ( 2 days after he became symptomatic). His symptoms included fever, sore throat, cough, nasal congestion, muscle aches, and shortness of breath. The subject recovered at home. He was not immunocompromised and had no other comorbidities. He had been working from home and did not report any other high-risk behavior.

No other subjects had any of the surveyed symptoms of COVID-19 after their injection.

The Massachusetts Department of Health COVID-19 Daily Dashboard reports the number of new cases each day. From April 15, 2020, and 90,889 to May 22, 2020, the total number of new cases was 62,726 [14]. Therefore, the rate of occurrence of new cases of COVID-19 cases in the state of Massachusetts was $0.91 \%(62,726 / 6,892,503)$ between April 
Fig. 2 Flowchart depicting image-guided corticosteroid patient population
71 patients presented for steroid injection from April 15, 2020 to May 22, 2020

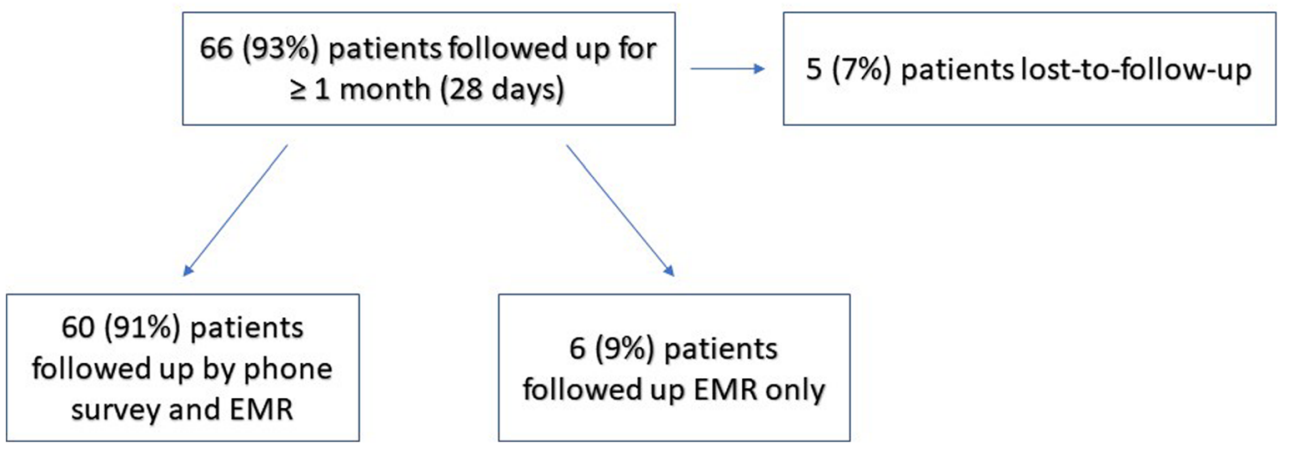

15 and May 22, 2020. There was no significant difference in the rate of occurrence of new cases of COVID-19 infection in the corticosteroid injection group $(1 / 66,1.52 \%)$ and the general population of the state of Massachusetts $(62,726 /$ $6,892,503,0.91 \%)(p=0.44)$. For the estimated proportion in the corticosteroid injection group of $1(1.6 \%)$, the exact binomial $95 \%$ confidence interval is $0.04-8.2 \%$.

\section{Discussion}

Our study examining outpatients who received image-guided corticosteroid injections for pain management during the lockdown phase of the COVID-19 pandemic found one subject who developed symptomatic COVID-19 infection 19 days after a tibiotalar joint infection. This translates to an infection rate of $1.52 \%$, which is not statistically significant from the rate of occurrence of new cases of COVID-19 in the general population in the state of Massachusetts $(p=0.44)$.

The onset of the COVID-19 pandemic was sudden and alarming. New discoveries about this virus are still being made daily and there remains much to be learned. One of the features of this virus is that it has a long latency period following exposure where a person can carry and shed virus particles without being symptomatic [7]. The risk of corticosteroid administration in the context of a latent infection is unknown. As stated in the warnings section for triamcinolone: "Chicken pox and measles can have a more serious or even fatal outcome in pediatric and adults patients on corticosteroids... The contribution of the underlying disease and/or prior corticosteroid treatment to the risk is also not known" [15]. Sytsma et al. performed a study of 15,068 joint injections and found a relative increased risk of 1.5 for vaccinated subjects developing influenza after an intra-articular corticosteroid injection compared with vaccinated control subjects [16]. Specifics were given for the vaccinated subjects who developed influenza infection, including corticosteroid dose (mean $66 \mathrm{mg}$, range $40-120 \mathrm{mg}$ ), injection of multiple joints at a single visit (37\%), multiple visits for injections (25\% with mean cumulative dose of $157 \mathrm{mg}$ ), corticosteroid type (methylprednisolone $79 \%$, betamethasone $11 \%$, triamcinolone $10 \%$ ), and joint injected (knee/hip 74\%, shoulder 26\%). However, similar information was not given for the subjects who did not develop influenza, and therefore, statistics were not performed. A notable difference between the Sytsma study and this current study is the corticosteroid type, with Sytsma et al. predominantly using methylprednisolone (79\% in influenza group) and our study predominantly using triamcinolone and betamethasone (98\%). Sytsma et al. also found that women younger than age 65 years were the group that was highest at risk and suggested that this group may need the high-dose vaccine in the setting of corticosteroid injection; this result should probably be considered when the COVID-19 vaccine becomes available [16].

Corticosteroids are known to have systemic absorption and effects. The two effects that are of the greatest concern for the present COVID-19 crisis are systemic immune depression and HPA-axis depression [10, 17-21]. Peripheral blood monocytes and lymphocytes drop in the first $24 \mathrm{~h}$, but recovery is seen by $24 \mathrm{~h}$ [10]. HPA-axis suppression as measured by decreased cortisol levels and decreased response to ACTHchallenge is seen within $24 \mathrm{~h}$ and persist in some persons at 4 weeks $[10,22]$. There is a dose-dependent relationship, as higher injected doses result in higher peak blood doses [23]. Particulate corticosteroid suspensions, which were used in all but one of the injections in this study, were designed with the goal of high intra-articular concentrations but low systemic levels, and therefore less HPA-axis suppression. However, it 
has been shown that suppression of the HPA-axis occurs at commonly used doses and that the duration of suppression may vary depending on the type of corticosteroid. For example, triamcinolone acetonide shows suppression at all doses up to $40 \mathrm{mg}$, but doses of $80 \mathrm{mg}$ are commonly injected, including at our institution. Betamethasone is more soluble than triamcinolone and HPA suppression is seen at doses of $6 \mathrm{mg}$ [24]. Dickson et al. studied facet joint corticosteroid injections with triamcinolone acetonide $40 \mathrm{mg}$ and found that HPA suppression occurs for an average of 4.4 days [11]. The depressed HPA-axis is of concern in the setting of the COVID-19 pandemic because if a patient were to encounter a stressful event such as a severe infection, s/he may not be able to mount a sufficient stress response to appropriately fight the infection, and a depressed HPA-axis is known to correlate with poor outcomes in critically ill persons $[8,25,26]$. Previously, a correlation between multiple pre-operative epidural injections and decreased stress response in spine surgery patients has been shown [27].

Corticosteroid injection-related adverse events do occur but are rare. In a study by Kim et al. of 11,980 facet joint injections in 6066 subjects, there were 8 major complications, 7 infectious spondylitis, and 1 Aspergillus infection, which spread to the spine. One of the subjects with infectious spondylitis had a history of infective endocarditis, and presumed reactivation of the infection by corticosteroid administration [12]. Seven out of the 8 subjects with major complications were older than 60 years, and the one that was younger was undergoing chemotherapy for non-small cell lung cancer. There were also two cases with diabetes mellitus [12]. Moreover, case reports of septicemia following soft tissue and intra-articular corticosteroid injection both with and without concomitant joint infection have been described [28].

There is little data available on the use of corticosteroids in the setting of the COVID-19 pandemic. A systematic review by Veronese et al. published in April 2020 found four studies investigating the use of systemic corticosteroids in the setting of COVID-19 pneumonia with mixed results. Two studies showed corticosteroids were detrimental, one that corticosteroids did not impact clinical outcome, and one that corticosteroids reduced the death risk by $62 \%$ [29]. Ling et al. found slower viral clearance of COVID-19 subjects who had received corticosteroids, although these were COVID-19 systemic treatment doses [30].

The major limitation for this study is that we do not know the true COVID-19 status of our subjects. We detected one symptomatic subject, but additional subjects may have had asymptomatic infection. In addition, this initial cohort of injections was performed in the second half of the lockdown, when the subjects had been mostly isolated for 1-2 months, and the prevalence of COVID-19 in this population is likely low. Ideally, a rapid test would have been available for all subjects immediately prior to the injection. However, at the time of this study, point-of-care testing was not available, and therefore, this study reflects our clinical practice at this particular point in time. Of note, if a test was available, our practice would not inject any patients who tested positive for COVID19. COVID-19 has also changed our practices in terms of screening for patients and PPE, and the degree of precaution required is unknown. These factors will be difficult to study, and we predict that we will continue our current practices for the forseeable future. Also, true prevalence of COVID-19 in the general population of Massachusetts is not known because universal testing is not available for the general public.

The sample size for this study was small (66 corticosteroid injection subjects with follow-up), which may not provide sufficient statistical power to detect differences between the groups. However, subject recruitment was determined by safety parameters and could not be increased for the time period of interests in this study (lockdown period). We plan to continue this study through the four recovery phases in our state, when exposures and risks are greater, and to see if COVID19 infection rates in our cohort remain comparable to population rates of occurrence of new cases. Finally, in this study, follow-up was available for some subjects for only 4 weeks following their injection. Joint and spine corticosteroid injections are known to have systemic effects of 4 and possible more weeks, and therefore, a larger study cohort with longer follow-up is needed to further evaluate the safety of injecting corticosteroids in the setting of the COVID-19 pandemic.

In conclusion, our study showed no significant difference in the rate of occurrence of new cases of COVID-19 infection in the corticosteroid injection group and the general population of Massachusetts during the lockdown phase of the COVID-19 pandemic. These findings may be helpful to inform future practice during a lockdown phase if a resurgence of COVID-19 occurs.

\section{Compliance with ethical standards}

Conflict of interest The authors declare that they have no conflict of interest.

Ethical approval All procedures performed in studies involving human subjects were in accordance with the ethical standards of the institutional and/or national research committee and with the 1964 Helsinki declaration and its later amendments or comparable ethical standards. This study was approved by the Partners Human Research IRB (Protocol \#: 2020P001307).

Informed consent The study was approved by the local Institutional Review Board (IRB) and HIPAA compliant. Verbal consent for participation in the study was obtained as per IRB protocol. 


\section{References}

1. Benyamin RM, Manchikanti L, Parr AT, Diwan S, Singh V, Falco FJE, et al. The effectiveness of lumbar interlaminar epidural injections in managing chronic low back and lower extremity pain. Pain Physician. 2012;15:E363-404.

2. Manchikanti L, Cash KA, McManus CD, Pampati V, Fellows B. Results of 2-year follow-up of a randomized, double-blind, controlled trial of fluoroscopic caudal epidural injections in central spinal stenosis. Pain Physician. 2012;15:371-84.

3. Lavelle W, Lavelle ED, Lavelle L. Intra-articular injections. Med Clin North Am. 2007;91:241-50.

4. Fascia D, Dalili D, Rennie W, Rowbotham E, Carne A, Robinson P. Recommendations of the British Society of Skeletal Radiologists: the safety of corticosteroid injections during the COVID-19 global pandemic [Internet]. 2020 [cited 2020 May 13]. Available from: https://www.bssr.org.uk/static/uploads/ forum/Musculoskeletal_Radiology_during_the_COVID-19 Global_Pandemic.pdf

5. British Society for Rheumatology: clinical guide for the management of patients with musculoskeletal and rheumatic conditions on corticosteroids during the coronavirus pandemic [Internet]. 2020 [cited 2020 May 18]. Available from: https://www.bssr.org.uk/ static/uploads/forum/13._CO0043_Specialty-guide-andcoronavirus_-MSK-corcosteroid_-v1.pdf.pdf

6. Shanthanna $\mathrm{H}$, Strand NH, Provenzano DA, Lobo CA, Eldabe S, Bhatia A, et al. Caring for patients with pain during the COVID-19 pandemic: consensus recommendations from an international expert panel. Anaesthesia. 2020;75:935-44.

7. Liu Z, Magal P, Seydi O, Webb G. A COVID-19 epidemic model with latency period. Infect Dis Model. 2020

8. Marik PE, Pastores SM, Annane D, Meduri GU, Sprung CL, Arlt $\mathrm{W}$, et al. Recommendations for the diagnosis and management of corticosteroid insufficiency in critically ill adult patients: consensus statements from an international task force by the American College of Critical Care Medicine. Crit Care Med. 2008;36:193749.

9. News \& Press: Patient Safety. New FactFinder on steriod injections and COVID-19 infection risk. [Internet]. 2020 [cited 2020 May 16]. Available from: https://www.spineintervention.org/news/506412/ New-FactFinder-on-Steroid-Injections-and-COVID-19-InfectionRisk.htm

10. Habib GS. Systemic effects of intra-articular corticosteroids. Clin Rheumatol. 2009;28:749-56.

11. Dickson RR, Reid JM, Nicholson WT, Lamer TJ, Hooten WM. Corticosteroid and cortisol serum levels following intra-articular triamcinolone acetonide lumbar facet joint injections. Pain Pract Off J World Inst Pain. 2018;18:864-70.

12. Kim BR, Lee JW, Lee E, Kang Y, Ahn JM, Kang HS. Intraarticular facet joint steroid injection-related adverse events encountered during 11,980 procedures. Eur Radiol. 2020;30:1507-16.

13. Reopening Massachusetts: what businesses can expect in phase 1 [Internet]. Massachusetts State Government; 2020 [cited 2020 Jun 23]. Available from: https://www.mass.gov/doc/reopeningmassachusetts-phase-one-summary/download

14. COVID-19 response reporting: COVID-19 daily dashboard [Internet]. Massachusetts Department of Public Health; [cited 2020 Aug 12]. Available from: https://www.mass.gov/infodetails/covid-19-response-reporting
15. Kenalog 10 injection (triamcinolone acetonide injectable suspension): uses, dosage, side effects, interactions, warning [Internet]. RxList. [cited 2020 May 1]. Available from: https://www.rxlist. com/kenalog-10-injection-drug.htm

16. Sytsma TT, Greenlund LK, Greenlund LS. Joint corticosteroid injection associated with increased influenza risk. Mayo Clin Proc Innov Qual Outcomes. 2018;2:194-8.

17. Habib G, Elias S, Abu-Elhaija M, Sakas F, Khazin F, Artul S, et al. The effect of local injection of methylprednisolone acetate on the hypothalamic-pituitary-adrenal axis among patients with greater trochanteric pain syndrome. Clin Rheumatol. 2017;36:959-63.

18. Lazarevic MB, Skosey JL, Djordjevic-Denic G, Swedler WI, Zgradic I, Myones BL. Reduction of cortisol levels after single intra-articular and intramuscular steroid injection. Am J Med. 1995;99:370-3.

19. Johnston PC, Lansang MC, Chatterjee S, Kennedy L. Intra-articular glucocorticoid injections and their effect on hypothalamic-pituitaryadrenal (HPA)-axis function. Endocrine. 2015;48:410-6.

20. Habib G, Jabbour A, Artul S, Hakim G. Intra-articular methylprednisolone acetate injection at the knee joint and the hypothalamicpituitary-adrenal axis: a randomized controlled study. Clin Rheumatol. 2014;33:99-103.

21. Broersen LHA, Pereira AM, Jørgensen JOL, Dekkers OM. Adrenal insufficiency in corticosteroids use: systematic review and metaanalysis. J Clin Endocrinol Metab. 2015;100:2171-80.

22. Abdul AJ, Ghai B, Bansal D, Sachdeva N, Bhansali A, Dhatt SS. Hypothalamic pituitary adrenocortical axis suppression following a single epidural injection of methylprednisolone acetate. Pain Physician. 2017;20:E991-1001.

23. Habib G, Jabbour A, Salman J, Hakim G, Haddad H. The effect of epidural methylprednisolone acetate injection on the hypothalamicpituitary-adrenal axis. J Clin Anesth. 2013;25:629-33.

24. Derendorf H, Möllmann H, Grüner A, Haack D, Gyselby G. Pharmacokinetics and pharmacodynamics of glucocorticoid suspensions after intra-articular administration. Clin Pharmacol Ther. 1986;39:313-7.

25. Ho JT, Al-Musalhi H, Chapman MJ, Quach T, Thomas PD, Bagley CJ, et al. Septic shock and sepsis: a comparison of total and free plasma cortisol levels. J Clin Endocrinol Metab. 2006;91:105-14.

26. Widmer IE, Puder JJ, König C, Pargger H, Zerkowski HR, Girard J, et al. Cortisol response in relation to the severity of stress and illness. J Clin Endocrinol Metab. 2005;90:4579-86.

27. Shin WS, Ahn DK, Kim MJ, Cho KJ, Go YR. Influence of epidural steroid injection on adrenal function. Clin Orthop Surg. 2019;11: $183-6$.

28. Kortelainen ML, Särkioja T. Fatal complications of intramuscular and intra-articular injections. Z Rechtsmed. 1990;103:547-54.

29. Veronese N, Demurtas J, Yang L, Tonelli R, Barbagallo M, Lopalco P, et al. Use of corticosteroids in coronavirus disease 2019 pneumonia: a systematic review of the literature. Front Med. 2020;7:170

30. Ling $\mathrm{Y}, \mathrm{Xu}$ S-B, Lin Y-X, Tian D, Zhu Z-Q, Dai F-H, et al. Persistence and clearance of viral RNA in 2019 novel coronavirus disease rehabilitation patients. Chin Med J (Engl). 2020;133:1039_ 43.

Publisher's note Springer Nature remains neutral with regard to jurisdictional claims in published maps and institutional affiliations. 